\title{
Complete Remission with Incomplete Hematological Recovery
}

National Cancer Institute

\section{Source}

National Cancer Institute. Complete Remission with Incomplete Hematological Recovery. NCI Thesaurus. Code C150587.

The disappearance of all signs of cancer in response to treatment with residual neutropenia (less than 1,000 per microliter), with or without complete platelet recovery. 